\title{
PERCEPÇÕES DE GRADUANDAS EM PEDAGOGIA SOBRE SUA FORMAÇÃO PARA O USO DAS TECNOLOGIAS EMERGENTES EM SALA DE AULA: UM ESTUDO DE CASO NA AMAZÔNIA OCIDENTAL
}

\author{
Delziana de Oliveira ${ }^{1}$, UNIR, deuzianeoliveira@gmail.com \\ Rafael Fonseca de Castro, UNIR, castro@unir.br
}

\begin{abstract}
Resumo
O presente artigo é um recorte de uma pesquisa de Mestrado que objetivou investigar as percepções de graduandas em Pedagogia (de 2018/2) de uma universidade localizada na Amazônia Ocidental brasileira, quanto ao uso das Tecnologias Emergentes (TE) em sua futura atuação docente. Tratou-se de um estudo de abordagem qualitativa, do tipo Estudo de Caso. Foi aplicado um questionário com questões abertas e fechadas a $100 \%$ da turma para a coleta de dados e adotada a análise textual discursiva para suas posteriores análises. Verificou-se a contradição de que a maioria das formandas compartilha a percepção do sentimento de preparo para o uso das TE em futuras práticas pedagógicas, mas que tal "formação" não foi adquirida ao longo do curso de Pedagogia, segundo o que indicam em suas respostas. Considerando nossas análises das percepções das Pedagogas, hoje formadas e algumas já atuando na Educação Básica, podemos inferir que, apesar do sentimento de preparo e do incentivo do curso a usarem as TE, a formação teórico-prática oferecida ao longo desse curso de Pedagogia não foi suficiente, pois, segundo elas, as teorias não deram o suporte necessário para o efetivo uso pedagógico das TE em sala de aula num futuro profissional.
\end{abstract}

Palavras-chave: Tecnologias emergentes. Formação de Professores. Pedagogia. Amazônia Ocidental.

\section{PERCEPTIONS OF UNDERGRADUATE PEDAGOGY STUDENTS ABOUT THEIR TRAINING FOR THE USE OF EMERGING TECHNOLOGIES IN THE CLASSROOM: A CASE STUDY IN WESTERN AMAZON}

\begin{abstract}
This article is a clipping of a Master's research that aimed to investigate the Pedagogy undergraduate students' (from 2018/2) perceptions, from a Brazilian Western Amazon university, regarding the use of Emerging Technologies (TE) in their future teaching activities. This was a qualitative approach study, such as Case Study. For data collection, a questionnaire with open and closed questions was applied to $100 \%$ of the class and the discursive textual analysis was adopted for further analysis. The contradiction founded was that most of the students shared the perception of preparedness for the use of TE in their future pedagogical practices, but that such "training" was not acquired during the Pedagogy course, according to what they indicate in their answers. Considering our analysis of Pedagogues perceptions, nowadays graduated and some already teaching in Basic Education, we can infer that, despite the feeling of preparation and encouragement from the Pedagogy course for the TE use, the theoretical-practical training offered throughout this course wasn't enough because, according to them, the theories did not provide the necessary support for the effective pedagogical use of TE in the classroom on a professional future.
\end{abstract}

Keywords: Emerging Technologies. Teacher Training. Pedagogy. Western Amazon.

\footnotetext{
${ }^{1}$ Bolsista CAPES de 2016 a 2018. Esta pesquisa contou com o apoio da Coordenação de Aperfeiçoamento de Pessoal de Nível Superior V. $18 \mathrm{~N}^{\mathrm{o}} 1$, julho, 2020 DOI: RENOTE
} 


\section{Introdução}

A junção da cultura globalizada ao que denominados Tecnologias Emergentes (TE) e os processos que as fomentam estão conduzindo uma constante reestruturação na organização do trabalho, na produção de bens e serviços, nas relações sociais e também na Educação. As TE estão corporal e digitalmente presentes no ambiente físico, no virtual, na casa, no trabalho, estão em praticamente todos os ambientes, lendo os signos que mediam as relações sociais sem interrupção.

A Educação necessita entender essas transformações e buscar soluções para superar os desafios impostos pelas mudanças delas decorridas. De acordo com Kenski (2013), o grande desafio posto é promover discussões críticas sobre o uso e a apropriação das TE para, assim, reconhecer sua relevância nos modos de ser e de agir dos indivíduos no cotidiano, bem como o seu potencial didático-pedagógico.

É notório que o desenvolvimento humano demanda educação escolar, o que é defendido por diversos estudiosos, como Vygotsky (1934/1982), Saviani (2014; 2009), Duarte (2001), Libâneo (2004) e Davydov (1988), para citar alguns. Embora a sociedade esteja em uma situação de crise causada pela fragmentação do pensamento humano, os próprios seres humanos são capazes de transcender, por meio da comunicação e da Educação, para uma perspectiva universal e emancipatória, como na perspectiva defendida por Paulo Freire (2011). Percebe-se, desta forma, como apregoa Saviani (2014; 2009), a legitimidade de uma Educação transformadora e comprometida com a emancipação dos homens.

A democratização de uma sociedade pelo ensino passa, necessariamente, pelo viés da compreensão da capacidade humana de manipular informações (principalmente, em um mundo digital) e disponibilizá-las socialmente com equidade. Corroboramos o que colocam Libâneo et al. (2012), quando estes defendem que, em uma sociedade da informação, é necessário que se forneçam as bases para dotar os sujeitos de competências e habilidades para a participação na vida social, econômica e cultural, para que não haja abertura a novas formas de divisão social.

De acordo com Kenski (2007), pensar a prática docente implica pensar o docente como ser um humano em desenvolvimento e que a formação docente não ocorre apenas na formação inicial, mas permanentemente. Para a formação da identidade profissional do professor, é necessário que o docente tenha tempo para se dedicar a estudos e formações continuadas, o que fortalecerá, entre outros conhecimentos, seu embasamento teórico e suas ações pedagógicas quanto ao uso das tecnologias em sua prática pedagógica.

A formação docente precisa ser compreendida como uma ação planejada para exercer determinada prática social. Assim, não se pode agir em prol da formação docente sem levar em consideração toda a complexidade advinda da trama social. Também há uma incerteza com relação à formação de professores para o uso das TE como instrumentos de mediação nos processos de ensino e de aprendizagem nas escolas. Sobre isso, Kenski (2007) comenta que as instituições de ensino, nos mais variados níveis, foram equipadas com televisores ou computadores, e depois com computadores e tablets, mas não tiveram o retorno refletido na aprendizagem dos educandos. Apresentadas, muitas vezes, como soluções milagrosas para os problemas na Educação, as tecnologias, sozinhas, não conseguem resolver os desafios educacionais que estão postos. Há que se investir em formação docente, inicial e continuada!

V. $18 \mathrm{~N}^{\circ} 1$, julho, 2020 RENOTE DOI: 
A formação docente precisa estar conectada às mudanças sociais e, para além de uma simples comprovação certificada de conhecimentos, mediante a complexidade do mundo globalizado, é necessário formar efetivamente professores para que utilizem as TE como recurso pedagógico de forma adequada e eficaz. Somente com professores preparados é que poderemos formar nas escolas cidadãos críticos que saibam lidar com autonomia e discernimento junto ao excesso de informações e às constantes inovações e transformações em todas as esferas sociais e áreas do conhecimento, como defendem Castro (2020), Kenski (2007) e outros pesquisadores Brasil e mundo afora.

Entendemos que a formação quanto ao uso das tecnologias não é mais o futuro da Educação, mas seu presente inevitável. Basta olharmos ao redor e percebermos o quanto as comunicações móveis fazem parte da vida das pessoas e o quão pouco essas ferramentas são utilizadas nas escolas públicas brasileiras. Implementar uma formação docente que atue teórica e objetivamente com o trabalho pedagógico permeado pelas TE é condição sine qua non para constituirmos escolas inclusivas (no mais amplo sentido da expressão) e efetivamente sintonizadas com as emergências do século XXI.

Para que a formação docente busque acompanhar os avanços tecnológicos da sociedade atual, a abordagem deste tema é de fundamental relevância, haja vista as preocupações diárias dos professores ao vislumbrarem a possibilidade de um trabalho de mediação pedagógica que possibilite maior acesso ao conhecimento científico pelos estudantes (Saviani, 2014; Duarte, 2001; Libâneo, 2004; Davydov, 1988) por meio de Tecnologias Emergentes (Castro, 2020).

No intuito de buscar melhor compreender essa problemática, utilizamo-nos, ao longo do texto, de autores vinculados à Teoria Histórico-Cultural ${ }^{2}$, à Pedagogia HistóricoCrítica e pesquisadores que tratam da relação educação-tecnologia. A presente escrita está organizada conforme disposto a seguir: esta Introdução; Material e métodos; Resultados e discussão; Conclusões e; Referências Bibliográficas.

\section{Material e Métodos}

Diante do contexto acima problematizado, foi realizada pesquisa ${ }^{3}$ de abordagem qualitativa (Bauer e Gaskell, 2002), do tipo Estudo de Caso (Gil, 2010) com formandas de um Curso de Pedagogia e docentes atuantes na Educação Básica do município de Porto Velho, estado de Rondônia, Amazônia Ocidental brasileira ${ }^{4}$.

O referido estudo teve o intuito de conhecer nuances e contradições a partir das percepções de graduandas (professoras em formação) e educadoras (professoras em atuação) acerca do uso pedagógico de TE em sala de aula. Considerou-se a necessidade de pensar a formação de professores para a atuação no âmbito escolar sem perder de vista a realidade concreta do acadêmico de Pedagogia, levando em consideração características

\footnotetext{
${ }^{2}$ Esta pesquisa integra o conjunto de investigações que compõem o Programa de Pesquisa Educação e Psicologia Histórico-Cultural: investigações teórico-práticas de processos educativos na Amazônia Ocidental (Portaria No 70/2019/PROPESQ/UNIR), vinculado ao Grupo de Pesquisa HISTCULT Educação, Psicologia Educacional e Processos Formativos. Mais detalhes em http://www.histcult.unir.br. ${ }^{3}$ Todos os procedimentos para a execução da pesquisa a qual as informações mencionadas neste artigo se referem foram aprovados pelo CEP/UNIR/Plataforma Brasil, Parecer 2.989.963, emitido em 30/10/2018.

${ }^{4}$ Região constituída pelos Estados do Amazonas, Acre, Rondônia e Roraima, detém 42,97\% da extensão territorial da Amazônia Legal e comporta cerca de 57\% das florestas da região, o que a torna a parte mais preservada da Amazônia brasileira, além de ser um estoque de biodiversidade sem igual no planeta. V. $18 \mathrm{~N}^{\mathrm{o}} 1$, julho, 2020 RENOTE DOI:
} 
e peculiaridades da região. Neste recorte, são apresentados e discutidos os resultados relativos às percepções das graduandas em Pedagogia.

O curso de Pedagogia que constituiu parte do lócus da pesquisa é ofertado por uma universidade multicampi, instalada em oito municípios do estado de Rondônia. Entre os cursos já ofertados pela Universidade, está o de Pedagogia. Este curso foi instituído por sua relevância no que se refere à formação inicial de professores que possam atuar profissionalmente nas escolas do estado de Rondônia e região. É ofertado no período matutino, com carga horária total de 3.480 horas. Seu tempo mínimo de integralização é de quatro anos e, o máximo, de seis anos.

O critério de seleção da turma de Pedagogia levou em consideração, exclusivamente, o fato de ser a turma de formandos no ano de efetivação da pesquisa (2018), visando à obtenção de uma avaliação atual do cenário de percepções sobre a temática abordada.

Participaram da pesquisa um total de 33 acadêmicos de Pedagogia e, para a coleta de dados, foi aplicado um questionário (Gil, 2010) composto por dez questões, sendo nove fechadas e uma aberta. Os dados foram organizados, sistematizados e analisados por meio de análise textual discursiva, nos moldes preconizados por Moraes (2003). Este tipo de análise se divide em quatro etapas: (1) desmontagem; (2) estabelecimento de relações, categorização; (3) captação do novo emergente e; (4) processo auto organizado final.

Seguindo os pressupostos metodológicos de Moraes (2003), primeiramente, foi realizada a desconstrução dos dados obtidos a partir das repostas das acadêmicas ao questionário, direcionando-os para o corpus da pesquisa - com leitura cuidadosa dos dados, tornando visível aquilo que não estava exposto explicitamente nas respostas.

Na segunda etapa, foi realizada nova e cuidadosa leitura do material da pesquisa e elaborada a categorização a partir de unidades significativas emergentes. Assim, a partir dos dados do questionário aplicado às formandas em Pedagogia, foram definidas e serão aqui discutidas (em formato de síntese, devido às limitações de espaço) as seguintes categorias de análise:

a) Percepção sobre a formação para o uso das TE: categoria que emergiu dos dados sobre o uso pedagógico das TE a partir da formação obtida no Curso de Pedagogia, pelas formandas.

b) Percepção sobre a importância da base teórico-prática: apresenta os dilemas e os desafios sociais que a formação docente enfrenta, os modelos de formação dualista, um pautado na prática e outro na teoria, e as implicações dessa formação inicial para o embasamento das práticas educativas a serem desenvolvidas pelas futuras professoras.

c) Percepção sobre a possibilidade de uso das TE na prática educativa: revela as contradições existentes entre a realidade da sociedade e a vivenciada pela escola no que diz respeito ao uso das TE em práticas pedagógicas.

Com as definições das categorias, passou-se à captação do novo emergente e à construção do texto, agora, com as inferências dos pesquisadores, mas não modificando a realidade inicial dos dados. A materialização dos elementos apresentados, a seguir, implica em um movimento de afastamento do material empírico, em um exercício de abstração, de maneira a expressar novas compreensões (Moraes, 2003). 


\section{Resultados e discussão}

Apresentadas as categorias de análise e cumprindo com a sequência preconizada por Moraes $(2003)^{5}$, a seguir, voltar-nos-emos às análises propriamente ditas dos dados.

\section{a) Percepção sobre a formação para o uso das TE}

Os dados sobre a percepção acerca do sentimento de preparo para a prática pedagógica com as TE têm por base a questão seis do questionário: "Você se sente preparado(a) para utilizar as tecnologias em sala de aula?’.

O Gráfico 1 apresenta a percepção das formandas de Pedagogia sobre o sentimento de preparo para o uso pedagógico das TE na sua futura prática docente:

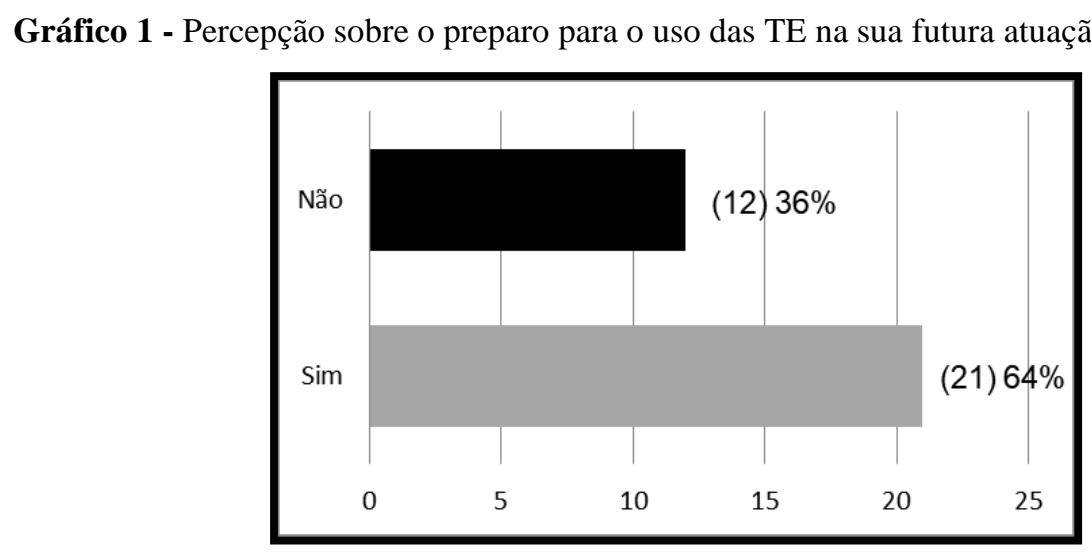

Fonte: Banco de dados da pesquisa (2018).

Constatou-se que $64 \%$ relataram que se sentiam preparadas para o uso das TE em suas futuras práticas pedagógicas, enquanto $36 \%$ afirmaram não se encontrarem preparadas para tal. $\mathrm{O}$ fato de a ampla maioria das formandas relatar estar preparada pode se dar ao fato de se tratar de uma nova geração, mais habituada ao uso de tecnologias no cotidiano. O uso de meios tecnológicos já faz parte de seu dia-a-dia e sabem fazer uso de parte considerável dos dispositivos mais utilizados socialmente. Mas há uma grande diferença entre utilizar socialmente no cotidiano e usar pedagogicamente em sala de aula como recurso didático diferenciado.

Para Castro (2020) e Kenski (2007), os professores não são formados para o uso pedagógico das tecnologias. Há problemas decorrentes da própria profissionalização do professor. Em recente pesquisa sobre os currículos dos cursos de Pedagogia de universidades federais, sediados em todas as capitais da Região Norte do Brasil, Castro (2020) constatou que, entre os currículos desses cursos, três ofertam apenas uma disciplina sobre tecnologia ao longo de quatro anos; um curso oferta duas disciplinas e; um curso oferta três. Dois cursos que ofertam uma disciplina sobre a relação Educação e tecnologia o fazem apenas em caráter optativo/eletivo, podendo, as futuras professoras, não cursarem nenhuma disciplina sobre essa importante temática para a sua formação ao longo de todo o curso de Pedagogia. Não se defende aqui que a simples oferta daria conta da formação nessa temática, mas a constituição curricular já sinaliza a importância que

\footnotetext{
${ }^{5}$ No caso do presente artigo, apresentamos somente os achados oriundos das perguntas fechadas, sendo os pressupostos de Moraes (2003) utilizados para a organização e a categorização dos dados da pesquisa. V. $18 \mathrm{~N}^{\circ} 1$, julho, 2020 RENOTE DOI:
} 
lhe é conferida. Kenski (2007) aponta que a diferença da prática não está no uso ou não uso das TE, mas na compreensão das possibilidades desses instrumentos como potencializadores das suas práticas pedagógicas.

\section{b) Percepção sobre a importância da base teórico-prática}

Apresentaremos, a seguir, nossa análise das percepções das então formandas em Pedagogia sobre a importância da base teórico-prática para a sua atuação pedagógica num futuro profissional, com base na questão sete do questionário: "O curso de Pedagogia, em sua opinião, forneceu base teórico-prática suficiente em sua formação para a utilização das tecnologias emergentes na sala de aula?".

O Gráfico 2 demonstra suas percepções sobre se a base teórico-prática para o uso pedagógico das TE, trabalhada ao longo do curso de Pedagogia, foi suficiente para sua formação enquanto futuras professoras:

Gráfico 2 - Percepções sobre a base teórico-prática em TE propiciada pelo curso de Pedagogia

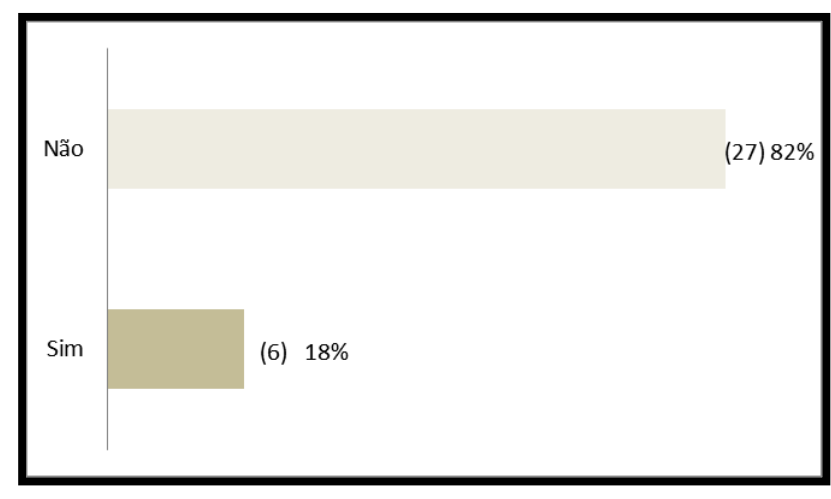

Fonte: Banco de dados da pesquisa (2018)

Ao revelarem suas respostas, verificamos que $82 \%$ das formandas afirmaram que não foi o suficiente. Porém, conforme demonstrado no Gráfico 1, 64\% delas se sentiam preparadas para o uso pedagógico das TE em sala de aula. Evidencia-se, aqui, que o sentimento de "preparo" parte da suposição de que possuem experiências autoformativas para a utilização pedagógica das diversas tecnologias em um futuro profissional. Também é provável que os números do Gráfico 1 não expressem a realidade para as acadêmicas, que poderiam se sentir levadas a responderem que sim, tendo em vista que já eram concluintes do curso e "não seria admissível" a falta de "preparo" nesse ponto de sua formação inicial.

Será que as acadêmicas, por sua própria iniciativa, desenvolveram concepções teóricas para práticas pedagógicas que se utilizam de tecnologias emergentes? Saviani (2014) e Duarte (2001) já destacavam a dicotomia entre a teoria e a prática como sendo a expressão da fragmentação do conhecimento, que é explicitada na dualidade com a supervalorização da prática em detrimento à teoria, o que acaba por legitimar o imediatismo, o pragmatismo, a superficialidade e, consequentemente, a caracterização da alienação do trabalho docente, de caráter mais técnico e cada vez menos reflexivo.

Por outro lado, levando em consideração princípios defendidos por Facci (2014), a escola sempre está imbricada às necessidades de cada sociedade e, de certa forma, o V. $18 \mathrm{~N}^{\mathrm{o}} 1$, julho, 2020 RENOTE DOI: 
papel do professor também atende a essas necessidades. Assim, suas ações nunca são neutras e, certamente, os professores têm certo discernimento de como ocorrem o ensino e a aprendizagem nas escolas. E é essa percepção que irá orientar sua prática pedagógica. Infere-se, então, que os professores, mesmo não sabendo exatamente qual teoria embasa suas práticas, ainda estão sob a influência de alguma perspectiva educacional, mesmo que em situação de alienação.

\section{c) Percepções sobre as possibilidades de uso das TE na prática educativa}

Para a composição e desdobramentos desta categoria, obtivemos os seguintes resultados ao analisarmos a percepção das acadêmicas sobre a possibilidade de utilização das TE propiciadas durante o curso de Pedagogia, com base na questão nove do questionário: "Houve incentivo ao longo do curso para o uso das TE?". Seguem os resultados, conforme disposto no Gráfico 3:

Gráfico 3 - Incentivo ao uso pedagógico das TE durante a formação no curso de Pedagogia

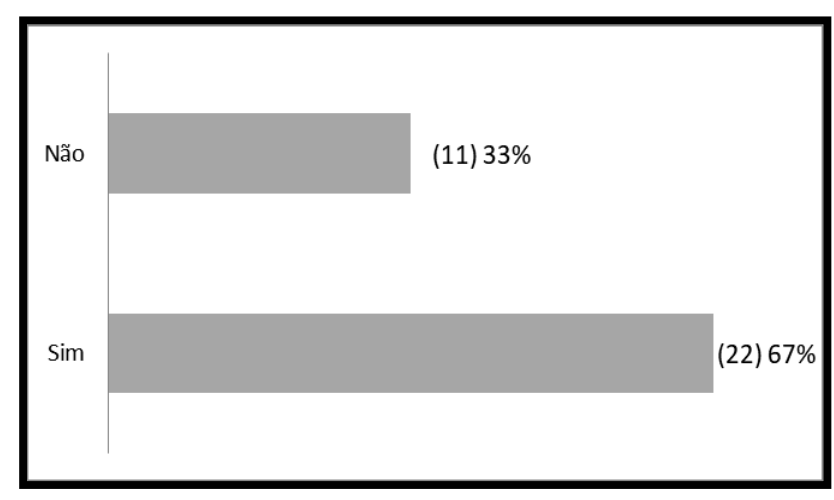

Fonte: Banco de dados da pesquisa (2018).

Constatou-se, em termos percentuais, que $67 \%$ dos graduandos têm a percepção de que houve algum tipo de incentivo para utilizarem as TE ao longo do curso de Pedagogia; em contrapartida, $33 \%$ declararam que não tiveram incentivo para o uso das TE durante o mesmo.

Consideramos uma disparidade grande nas respostas, tendo em vista que são acadêmicas que perfizeram o mesmo percurso ao longo do curso. Voltando ao estudo empreendido por Castro (2020), a universidade que constitui o lócus da pesquisa foi a única na qual se constatou que, no currículo do curso de Pedagogia, oferta três disciplinas cuja temática central é a relação Educação e tecnologia. Neste caso, o número expresso no Gráfico 3 tende a refletir a realidade. Há, também, contudo, a possibilidade das onze graduandas (33\%) que relataram não serem incentivadas pelo curso ao uso pedagógico das TE terem se manifestado de forma mais crítica do que as demais, tendo em vista, como já apontamos aqui, que a mera oferta de disciplinas não garante formação uma pedagógica adequada.

Devemos enfatizar que a Educação desvinculada da sua prática social (entendendo-se, aqui, que as formandas em Pedagogia e os estudantes das escolas estão inseridos em uma sociedade permeada pelas TE) torna-se incoerente, pois a apropriação que se adquire do conhecimento produzido de forma histórica pela sociedade, como um todo dialético, está condicionada às circunstâncias concretas em que vivem os indivíduos. V. $18 \mathrm{~N}^{\mathrm{o}} 1$, julho, 2020 RENOTE DOI: 
O descompasso que ocorre entre as mudanças na sociedade e as que ocorrem no interior das instituições educacionais (escolas e universidades) tem influência direta no sistema público de ensino, o que prejudica sua democratização.

Saviani (2009) declara que, tanto para garantir a formação do corpo docente de forma consistente, quanto para dar acesso a um ambiente escolar adequado à prática educativa, em que haja a possibilidade de uso dos recursos mais modernos, é necessário o provimento de recursos financeiros e reformas estruturantes, o que é, atualmente, um dos grandes desafios a serem enfrentados pela Educação brasileira, em particular na Região Norte do país.

É preciso acabar com a duplicidade pela qual, ao mesmo tempo em que se proclamam aos quatro ventos as virtudes da educação exaltando sua importância decisiva num tipo de sociedade como esta em que vivemos, classificada como "sociedade do conhecimento", as políticas predominantes se pautam pela busca da redução de custos, cortando investimentos. Faz-se necessário ajustar as decisões políticas ao discurso imperante (p. 153).

A partir de Saviani, perguntamo-nos: que estrutura estamos disponibilizando nas escolas e mesmo nas universidades públicas para a formação e para a prática pedagógica voltadas ao uso das tecnologias? De acordo com os autores Kenski (2007), Duarte (2008) e Saviani (2009), a alcunha de "sociedade do conhecimento" se tornou uma ilusão teórica ainda longe da realidade prática escolar brasileira. Admite-se que a sociedade passa por grandes transformações tecnológicas, mas a escola não acompanha seu ritmo. E a universidade, acompanha? Em nossa avaliação, não cabe o uso do termo "sociedade do conhecimento", pois esse saber global propalado não é um conhecimento acessível a todos. Entender essa historicidade de forma crítica é uma condição para que as TE sejam usadas efetivamente como instrumentos de mediação do ensino e não como mais um elemento de exclusão social.

Considerando os resultados aqui apresentados em formato de síntese, é evidente que a superação da visão limitante das experiências pedagógicas com as TE deve ser discutida frente às novas necessidades advindas das transformações sociais, visto que o ensino sistematizado pelas escolas está dissociado do uso das TE disseminadas na sociedade e historicamente situadas. Oferecer uma formação adequada relacionada à utilização das TE, que humanize o futuro professor em meio à formação inicial que também é intelectual, é um dos desafios para a construção de uma sociedade mais justa, igualitária e democrática. Para que a sociedade da informação possa se materializar, efetivamente, em uma sociedade do conhecimento para todas e todos.

Destaca-se, ainda, a defesa da Educação como máxima prioridade, fundamentalmente, no quesito da formação dos educadores para o adequado uso das TE, bem como em disponibilizar estrutura tecnológica e condições de trabalho nas escolas públicas. Isso deveria ser definido como o eixo de um projeto de desenvolvimento nacional em que a Educação seja efetivamente encarada como prioridade, valorizando o ser humano como um ser histórico e dinâmico. Saviani (2009) afirma que estrutura e recursos adequados nas escolas contribuiriam não só para a superação do problema da Educação de má qualidade, mas, também, simultaneamente, de outros problemas do país, como da saúde, da segurança, dos transportes, do fornecimento de energia elétrica, entre outros. Consequentemente, diminuiria a falta de emprego e a pobreza. "Infelizmente, porém, as tendências que vêm predominando na Educação brasileira caminham na contramão desta proposta" (SAVIANI, 2009, p. 153). 
Defende-se, aqui, a concepção histórica do ser humano para exercer o papel do ensino através de conceitos científicos (Vygotsky, 1934/1982), promovendo e desenvolvendo um ensino sistematizado dos conteúdos (Davydov, 1988) em que a prática educativa aconteça de forma envolvente e comprometida com a formação de indivíduos em sua plenitude (Libâneo, 2004), por meio do uso pedagógico das tecnologias emergentes típicas da segunda década do século XXI.

\section{Considerações}

Por meio do presente artigo, buscou-se apresentar uma elaboração contextual a respeito da percepção dos processos pedagógicos relacionados ao uso das Tecnologias Emergentes por formandas de um Curso de Pedagogia no contexto de uma universidade situada na Amazônia Ocidental brasileira (de forma sintética, respeitando as normas deste periódico), problematizando sobre o ensinar e o aprender em meio à revolução tecnológica que permeia a sociedade contemporânea.

O processo de transformação tecnológica desenvolvido na sociedade transcende as instituições em termos de formação docente, impondo limites na esfera da atuação educacional, desafios e possibilidades pedagógicas. A problemática abordada nesta pesquisa, em forma de Estudo de Caso, destacou um ponto de partida para possíveis debates sobre a necessidade de as instituições de ensino explorarem mais profundamente as TE, desde a formação inicial de professores, no intuito de colocar em prática um modelo pedagógico significativo, abrindo espaço para a inclusão das TE nos currículos da formação inicial de professores e nas salas de aula das escolas.

As questões aqui abordadas serviram para investigar a formação docente para o uso das TE frente a pressupostos relacionados às exigências demandadas pela sociedade contemporânea, num contexto de transição, impostas pelos avanços tecnológicos e a necessidade de se promover uma Educação dialética e emancipatória (Saviani, 2009; Freire, 2011).

Os aspectos apresentados foram analisados ressaltando, principalmente, as percepções das formandas de 2018 de um curso de Pedagogia sobre sua formação para o uso pedagógico das TE, como também a motivação dada pelo curso para o uso pedagógico das tecnologias em sala de aula. Discutiu-se, igualmente, as relações entre teoria e prática e a possibilidade de formar adequadamente as futuras educadoras visando a um uso eficiente das TE em suas futuras ações docentes.

De acordo com a análise do questionário aplicado às formandas, pode-se inferir que a maioria das formandas do curso de Pedagogia têm a percepção de estarem preparadas para ingressarem no exercício profissional - embora esse sentimento apresente-se de maneira contraditória. Elas se sentem aptas a colocarem em prática o uso das TE, mas, em suas percepções, tal preparo não foi adquirido pela base teórico-prática propiciada durante o curso de Pedagogia. Embora afirmem que houve incentivo ao longo do mesmo para o uso das TE, infere-se que este "preparo" é fruto de esforço próprio, de maneira autodidata, espontaneísta e não institucional.

$\mathrm{O}$ uso de TE conectadas à internet pode ser um recurso de mediação do ensino eficaz, com possibilidades para apropriação de conhecimentos conceituais, desde que se repense a matriz curricular e sejam agrupados modelos didáticos que aliem a teoria e à 
prática pedagógica, incorporando os recursos tecnológicos, típicos de cada tempo histórico, na formação inicial de professores e também em sua formação continuada.

A Licenciatura em Pedagogia deve proporcionar uma formação que possibilite a seus egressos formação para a utilização das TE pedagogicamente, e não apenas tecnicamente. Partindo dessa prerrogativa, será viável que as futuras professoras saibam utilizar as TE na sala de aula como instrumento de mediação dos conhecimentos sistematizados, com autonomia e criticidade, facilitando as aprendizagens dos milhões de educandos nas escolas do país, incluindo aqueles residentes na Região Amazônica brasileira.

É a nós perceptível que se faz urgente a construção de novos projetos, programas e políticas de formação, inicial e continuada, a fim de que sejam adotados procedimentos que possam proporcionar perspectivas de desenvolvimento profissional aos professores, considerando as condições atuais voltadas à Pedagogia, propiciando uma nova transformação social sem prescindir dos avanços tecnológicos emergentes.

\section{Referências Bibliográficas}

BAUER, Martin W. GASKELL, George. Pesquisa Qualitativa com Texto, Imagem e Som: um manual prático. Petrópolis: Vozes, 2002, 516p.

CASTRO, R. F. de. Tecnologias Emergentes e Formação de Professores: o que as grades curriculares de cursos de Pedagoga sinalizam? Múltiplos Olhares sobre a Formação de Professores no Brasil. (Orgs.) SILVA, Marijâne S.; PEDROSA, Neide B.; ISOBE, Rogéria M. R. Porto Velho: EDUFRO, 2020. p. 1-15.

DAVYDOV, V. V. La enseñanza escolar y eldesarrollo psíquico. Havana: Editorial Progresso, 1988. 278p.

DUARTE, N. Vigotski e o "aprender a aprender": Crítica às Apropriações Neoliberais e Pós-modernas da Teoria Vigotskiana. 2. ed. São Paulo: Autores Associados, 2001. 269p.

FACCI, M. G. D. Professora, é verdade que ler e escrever é uma coisa fácil? - Reflexões em torno do processo ensino-aprendizagem na perspectiva vigotskiana. In: Psicologia Histórico-Cultural: contribuições para o encontro entre a subjetividade e a educação. MEIRE, Marisa Eugênia Merillo. FACCI, Marilda Gonçalves Dias (Orgs.). São Paulo: Casa do Psicólogo, 2014. p. 135-155.

FREIRE, P. Pedagogia da autonomia: saberes necessários à prática educativa. 43. ed., São Paulo: Paz e Terra, 2011. 166p.

GIL, Antônio C. Como elaborar projetos de pesquisa. 5 ed. São Paulo: Editora Atlas, 2010 .

KENSKI, V. M. Educação e Tecnologia: o novo ritmo da educação. SP: Papirus, 2007. $144 \mathrm{p}$.

Tecnologias e Tempos Docente. SP: Papirus, 2013. 176p. 
LIBÂNEO, J. C. A didática e a aprendizagem do pensar e do aprender: a Teoria Histórico-cultural da Atividade e a contribuição de Vasili Davydov. Revista Brasileira de Educação, São Paulo, v.1, n. 27, 2004. p. 5-24.

MORAES, R. Uma tempestade de luz: a compreensão possibilitada pela análise textual discursiva. In: Ciência e educação. Bauru, v. 9, n. 2, 2003. p. 191-211.

SAVIANI, D. Formação de professores: aspectos históricos e teóricos do problema no contexto brasileiro. In: Revista Brasileira de Educação v. 14 n. 40 jan./abr. 2009. 143$155 \mathrm{p}$.

O lunar de Sepé: paixão, dilemas e perspectivas na educação. São Paulo: Autores Associados, 2014. 181p.

VYGOTSKY, L. S. Obras Escogidas Tomo II (Pensamiento Y Lenguaje). Moscú: Editorial Pedagógica, 1934/1982. 484p. 